\title{
O PAPEL DO FESTIVAL \\ GASTRONÔMICO DE TAQUARUÇU NA DEFINIÇÃO DA GASTRONOMIA DE TOCANTINS/TO
}

THE ROLE OF THE GASTRONOMIC FESTIVAL OF TAQUARUÇU IN DEFINING THE GASTRONOMY OF TOCANTINS/TO

EL PAPEL DEL FESTIVAL GASTRONÓMICO DE TAQUARUÇU EN LA DEFINICIÓN DE LA GASTRONOMÍA DE TOCANTINS/TO

Franksley Gomes dos Santos

Mestre em Hospitalidade pela Universidade Anhembi Morumbi

São Paulo, São Paulo, Brasil

fran35sp@hotmail.com

Sênia Bastos

Universidade Anhembi Morumbi

Docente do Mestrado em Hospitalidade da Universidade Anhembi Morumbi Doutora em História Social pela Pontifícia Universidade Católica de São Paulo

São Paulo, São Paulo, Brasil senia@anhembimorumbi.edu.br

Data de Submissão: 15/04/2016

Data de Aprovação: 20/07/2016

RESUMO: A associação da gastronomia à tradição e ao patrimônio fundamenta estratégias de marketing dos destinos turísticos. Com o intuito de incrementar a visitação turística, valorizar a culinária regional, incentivar o empreendedorismo na área gastronômica, trazer divisas para a região e divulgar os produtos típicos da culinária tocantinense, o governo municipal de Palmas patrocina a edição anual do Festival Gastronômico de Taquaruçu. Em virtude de sua importância no campo da gastronomia, constitui objeto de análise do presente estudo, ao que se recorre às receitas coletadas no Estado por Parrião (2009), a fim de caracterizar as principais técnicas e ingredientes predominantes nas suas diferentes regiões. De natureza qualitativa, apoia-se no método exploratório e descritivo, e compreende a realização de entrevistas com 
pessoas de reconhecido saber sobre a cozinha do Tocantins. Fundamenta-se nos registros fotográficos e nos documentos da Secretaria da Comunicação Social (Secom) de quatro edições do Festival, bem como na entrevista realizada com o seu organizador. Dentre os resultados, constata-se que, apesar de seu papel na criação de uma gastronomia para esse Estado em via de consolidação, o Festival não divulga as manifestações e as expressões culinárias e alimentares tradicionais ainda existentes.

PALAVRAS CHAVE: Gastronomia. Herança culinária. Tocantins/TO.

ABSTRACT: The association between gastronomy, tradition and heritage forms the basis of marketing strategies for tourist destinations. In order to increase tourism, add value to the regional cuisine, encourage entrepreneurship in the area of gastronomy, bring income to the region, and advertise the traditional products of the Tocantins cuisine, the municipal government of Palmas sponsors the annual Gastronomic Festival of Taquaruçu. Due to the importance of this festival in the field of gastronomy, it is the object of analysis of this study, which examines recipes collected in the State by Parrião (2009), in order to characterize the main techniques and predominant ingredients used in the different regions of the state. This is a qualitative study that uses exploratory and descriptive methods. It consists of interviews with people with recognized knowledge about the cuisine of Tocantins. It is based on photographic records and documents of the Secretaria da Comunicação Social (Secretariat of Social Communication - Secom) taken over four years of the Festival, as well as an interview with the organizer. Among the results, it was observed that despite its role in creating a cuisine for the State that is in the process of consolidation, the Festival does not disseminate the culinary and dietary manifestations and expressions that still exist.

KEYWORDS: Gastronomy. Culinary heritage. Tocantins/TO.

RESUMEN: La asociación de la gastronomía a la tradición y al patrimonio fundamenta las estrategias de marketing de los destinos turísticos. Con el propósito de incrementar la visitación turística, valorizar la culinaria regional, incentivar el emprendedorismo en el área gastronómica, traer divisas para la región y divulgar los productos típicos de la culinaria de Tocantins, el gobierno municipal de Palmas patrocina la edición anual del Festival Gastronómico de Taquaruçu. En virtud de su importancia en el campo de la gastronomía, constituye el objeto de análisis del presente estudio, en el que se recurre a las recetas recogidas en el Estado por Parrião (2009) a fin de caracterizar las principales técnicas e ingredientes predominantes en sus distintas regiones. De naturaleza cualitativa, se apoya en el método exploratorio y descriptivo, y comprende la realización de entrevistas con personas de reconocido saber sobre la cocina de Tocantins. Se fundamenta en los registros fotográficos y en los documentos de la Secretaría de Comunicación Social (Secom) de cuatro ediciones del Festival, así como en la entrevista realizada con su organizador. Entre os resultados se constata que, a pesar de su papel en la creación de una gastronomía para ese Estado en vías de consolidación, el Festival no divulga las manifestaciones y las expresiones culinarias y alimentarias tradicionales aún existentes.

PALABRAS CLAVE: Gastronomía; Herencia culinaria; Tocantins/TO.

INTRODUÇÃO 
tecnologias de comunicação e meios de intercâmbio (blogs, sites de avaliação, aplicativos de smartphones) conferem à gastronomia visibilidade e importância (Kesimoglu, 2015).

Último estado da federação a ser criado no Brasil (1988), a identidade de Tocantins encontra-se em construção, processo que compreende a definição de sua gastronomia, tema da presente reflexão시 por meio da análise do Festival Gastronômico de Taquaruçu.

A definição de uma determinada gastronomia implica um processo de "invenção", cujo protagonista, no presente caso, é o próprio Estado, quer por ter importante papel nessa ação, quer por omitir-se a esse processo, compactuando com o resultado. Trata-se de uma abstração constantemente negociada e vinculada ao patrimônio, cujo processo compreende a valorização de determinados ingredientes, heranças culinárias e apropriação de legados compartilhados com outros estados do país.

Convenientementevalorizada comoum atração, essa herança culinária diferencia o destino e o potencializa frente aos concorrentes, fator que tem motivado a ampliação dos estudos sobre turismo gastronômico, a ponto de se estabelecerem conexões entre produtos alimentares e destinos turísticos (Kesimoglu, 2015).

No Brasil predomina o modelo que ressalta os pratos típicos associados a cada Estado da Federação mediante estratégias de marketing destinadas a conferir-Ihes visibilidade, todavia os modos de fazer e as matérias-primas não se limitam a uma dada localidade. A gastronomia é mais ampla do que um conjunto de pratos típicos, mas a diversidade não constitui apelo valorizado nos planos de marketing, tampouco as tradições e as histórias desses legados. Nesse sentido, Dória (2014) sugere a investigação das reminiscências dos povos formadores da cozinha local e a desconstrução da abordagem regionalista resultante da adoção da delimitação sociopolítica estabelecida pelo Instituto Brasileiro de Geografia e Estatística (IBGE).

A associação da gastronomia à tradição e ao patrimônio tem sido o aporte das estratégias dos destinos turísticos (Kesimoglu, 2015). Com o intuito de

1 O presente artigo é resultado da dissertação intitulada "Da criação do Estado de Tocantins à invenção de sua gastronomia", defendida na Universidade Anhembi Morumbi em 2014. 
incrementar a visitação turística, valorizar a culinária regional, incentivar o empreendedorismo na área gastronômica, trazer divisas para a região e divulgar os produtos típicos da culinária tocantinense, o governo municipal patrocina a edição anual do Festival Gastronômico de Taquaruçu desde 2007. Atrativo turístico do município de Palmas, o Festival é organizado e divulgado pela Agência Municipal de Turismo nos cenários regional e nacional. Em virtude de sua importância no campo da gastronomia, constitui objeto de análise do presente estudo, ao que se recorre às receitas coletadas no Estado por Parrião (2009) a fim de caracterizar as principais técnicas e ingredientes predominantes nas suas diferentes regiões.

De natureza qualitativa, apoia-se no método exploratório e descritivo, compreendendoa realização de entrevistas com pessoas de reconhecido saber sobre a cozinha do Tocantins. Fundamenta-se nos registros fotográficos da Secretaria da Comunicação Social (Secom) das edições do festival relativas a 2007 (34 fotografias), 2009 (66 fotografias) e 2011 (14 fotografias), materiais disponibilizados no site da edição de 2013, bem como na entrevista realizada com o organizador do Festival.

O artigo se divide em sete partes, incluída esta introdução. Discorre sobre a criação do Estado e o caracteriza, visto que, para compreender a "invenção" dessa gastronomia, faz-se necessário investigar o contexto na qual se inscreve. Especifica a metodologia, conceitua cozinha, culinária e gastronomia, ao que é seguido por uma abordagem da cozinha de Tocantins. O Festival Gastronômico de Taquaruçu é por fim analisado mediante análise de registros fotográficos, documentos e entrevista e finaliza-o a conclusão.

\section{A CRIAÇÃO DO ESTADO DE TOCANTINS E CARACTERIZAÇÃO}

O Estado de Tocantins localiza-se na região Norte do país (figuras 1 e 2). Faz divisa ao Norte com Maranhão e Pará, ao Sul com Goiás, ao Leste com Piauí, Maranhão e Bahia, e a Oeste com Pará e Mato Grosso. Segundo o IBGE (2010), sua área é de $277.720,520 \mathrm{~km}^{2}$, constituída por planaltos e chapadões (cujo ponto mais elevado, com cerca de 1.340 m de altitude, localiza-se na Serra das Traíras, Município de Paranã), com predomínio de cerrado (87\%) e clima tropical 
semiúmido. Sua população vivenciou um lento processo até chegar a ser um estado independente, dotado de autonomia política. Inicialmente o processo de emancipação sociopolítica foi liderado pelo português e desembargador Joaquim Theotônio Segurado.

Figuras 1 e 2 - Mapa do Brasil, com ênfase ao Estado de Tocantins, e Mapa do Estado do Tocantins.
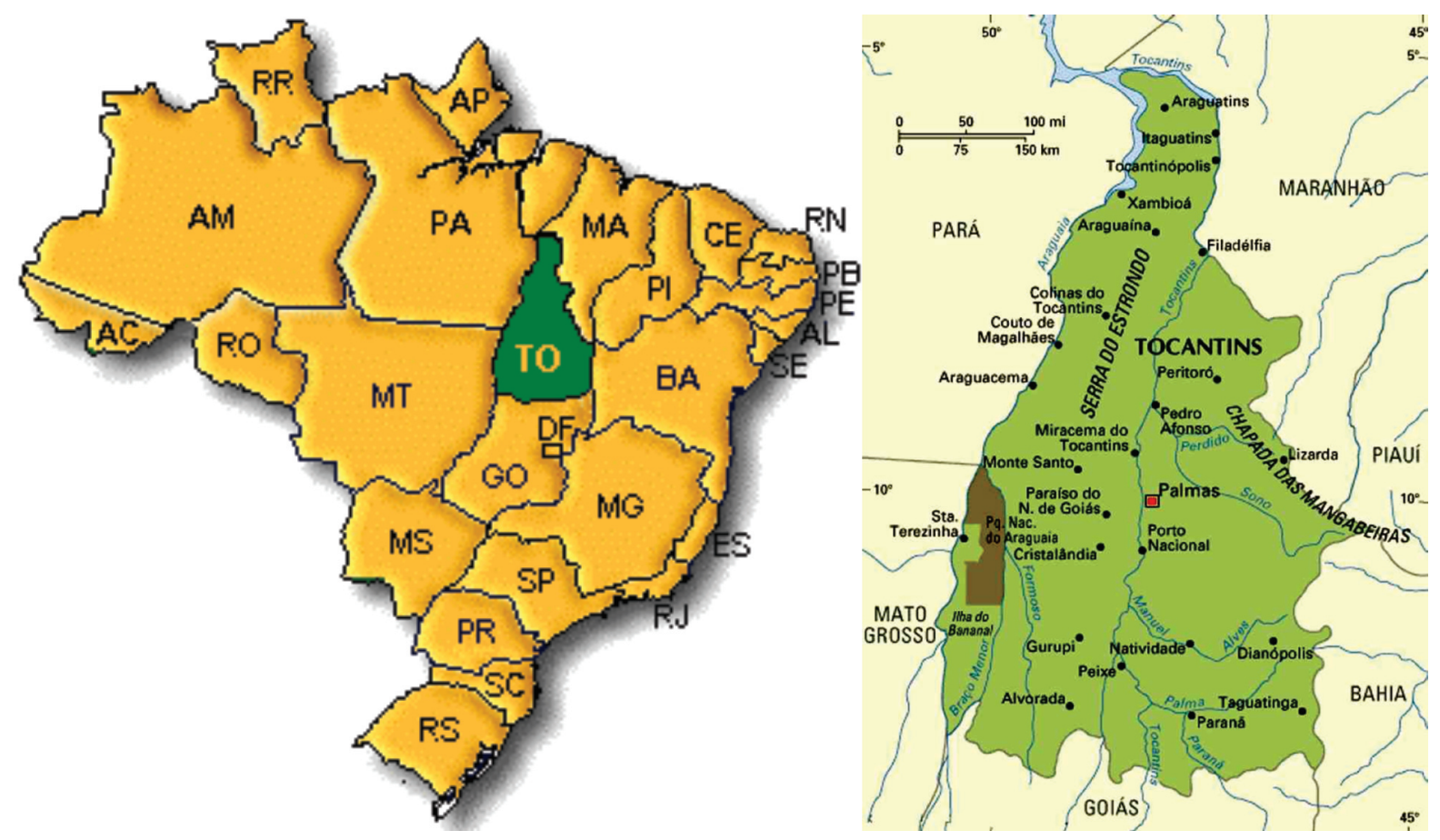

Fonte: Guia Net (2013).

De acordo com Cavalcante (2003), o processo se desenvolveu ao longo de 179 anos, até ser publicada a criação dessa nova federação do Brasil, em 1988. Embora ações anteriores a 1809 sejam apontadas a favor de sua separação do Estado de Goiás, esse ano constitui o ponto de partida oficial, em virtude da publicação de um alvará, dividindo a Capitania de Goiás em duas comarcas, a do Sul e a do Norte.

O movimento de autonomia do Norte de Goiás foi articulado por lideranças políticas e contou com a expressiva mobilização popular, inicialmente na cidade de Porto Nacional, durante os anos de 1956 a 1960, resultando na criação do Movimento de Pró-Criação do Estado de Tocantins, no dia 13 de maio de 1956, considerado o dia histórico do Estado (Cavalcante, 2003, p. 64).

Em 1981, na cidade de Brasília, intelectuais ali radicados, com o apoio dos fazendeiros, criaram a Comissão de Estudos dos Problemas do Norte Goiano (Conorte) para organizar a luta pela autonomia e a criação do Estado do Tocantins (Oliveira, 2004, p. 43). 
O discurso autonomista e separatista do Estado de Goiás fundamentava a criação de um novo Estado. Apoiava-o as especificidades territoriais (recursos minerais), o potencial hídrico (rios Araguaia e Tocantins) e rodoviário (BelémBrasília e Transamazônica), além dos aspectos econômicos (agropecuária). Demonstrava o seu escasso desenvolvimento econômico por parte do governo federal e pelo Estado de Goiás e reclamava autonomia para autogerir a região e atender o seu povo, bem como as outras regiões do país, com a exportação de produtos agropecuários e a exploração das riquezas ainda inexploradas (Oliveira, 2004, p. 37).

Redigida pelo deputado José Wilson Siqueira Campos, a ementa pela criação do Estado de Tocantins foi votada e aprovada no dia 5 de outubro de 1988 e, a 7 de dezembro desse ano, Miracema do Norte torna-se sua capital provisória até sua fundação definitiva no ano seguinte.

Superada essa etapa, seguiu-se a definição da localização da nova capital. Ponto estratégico para escoamento de produtos, entre o município de Porto Nacional e Taquaruçu, entre o rio Tocantins e a Serra do Carmo, a área escolhida localiza-se estrategicamente na região central do Estado de Tocantins. Sua denominação decorre da grande quantidade de palmeiras existente no local, bem como da Comarca São João da Palma, onde se desenvolveu o movimento separatista do Norte goiano. O plano urbanístico de Palmas contou com a participação do arquiteto Luís Fernando Cruvinel Teixeira e a capital definitiva foi para lá transferida no dia 01 de janeiro de 1990.

\section{DA COZINHA À GASTRONOMIA}

Necessidade básica da humanidade em termos biológicos e fisiológicos, a alimentação apresenta importante aspecto cultural (Abreu; Viana; Moreno; Torres, 2001). De acordo com Maciel (2001), tratar a alimentação implica refletir sobre a relação da cultura com a natureza e compreender as técnicas desenvolvidas para o cultivo, a conservação e o preparo dos alimentos:

[...] a alimentação refere-se a um conjunto de substâncias que uma pessoa ou um grupo costuma ingerir, implicando a 
produção e o consumo, técnicas e formas de aprovisionamento, de transformação e de ingestão de alimentos. Deste modo, a alimentação vai além do biológico, relacionando-se com o social e o cultural. (Maciel, 2004, p. 26).

A seleção do que e como comer e da técnica a ser adotada na elaboração ou na conservação do alimento também é permeada por aspectos simbólicos, variam no tempo e no espaço, de acordo com a cultura e a identidade do grupo (Flandrin; Montanari, 1998; Santos, 2005, 2011). O aspecto identitário implícito na alimentação é destacado por Cascudo (2004, p. 384): "a identidade alimentar não apenas fixa a continuidade cultural, mas a contiguidade do grupo na extensão do social".

A alimentação engloba fatores relacionados à culinária e à comensalidade e são transmitidos de geração a geração (Carneiro, 2005, p. 72). Para Maciel (2004, p. 26), a culinária compreende as "técnicas que transformam os ingredientes em comida". Tanto a cozinha quanto a culinária integram o sistema alimentar de um povo sendo incorreto considerá-las sinônimo. A esse sistema também se inserem os produtos e os "hábitos e comportamentos relativos à alimentação" (Maciel, 2004, p. 26). A originalidade da cozinha, segundo Aron (1989, p. 282), "depende da diversidade e engenho das transformações", ao que acrescenta: "cozinheiros criativos estão combinando estilos, técnicas, ingredientes e sabores de todos os cantos do globo, muitas vezes em um único prato" (Aron, 1989, p. 291).

Na cena contemporânea, convencionou-se a denominação gastronomia, ${ }^{2}$ termo de origem grega que se refere ao estudo ou à observância das leis do estômago (Franco, 2001, p. 35) e designa o universo da alimentação. Referese às novas técnicas empregadas para a criação de certos pratos, utilização de produtos regionais e adoção de novas técnicas ou novos conceitos, como a nouvelle cuisine surgida na França na década de 1960, que se utiliza de ingredientes frescos, embora, de acordo com Franco (2001, p. 257), "algumas técnicas e preparações da nouvelle cuisine, que passam por inéditas, são na verdade resgatadas de outros tempos ou de outras culturas".

2 O termo reúne a junção de gaster (ventre, estômago), nomo (lei) e do sufixo ia, também denominado por gastrologia. 
A gastronomia se desenvolve ao buscar novas formas e técnicas de preparação dos alimentos, sem perder as sutilezas da preparação para não comprometer suas raízes (Revel, 1996, p. 180). Nesse contexto, aponta-se a valorização da cozinha popular, resgatada com o intuito de consolidá-la. Por vezes, esse resgate é documentado em livros, nos festivais gastronômicos, promovidos por autoridades locais, ou até mesmo propalado por chefs de cozinha.

Para resgatar uma determinada cozinha, de acordo com Revel (1996, p. 181), "o único remédio está no retorno à simplicidade e à qualidade" e salienta que "esse retorno à simplicidade ou permanece puramente teórico, ou não é acompanhado de nenhuma nova invenção gastronômica".

Difícil de realizar, a gastronomia resulta do debate entre a complexidade do saber fazer e o aspecto natural das preparações. Prescreve a preservação das receitas antigas, a utilização dos recursos naturais de uma determinada região e "permanece fiel a certo estilo de cozinha sem tentar introduzir elementos estranhos" (Revel, 1996, p. 183). Nesse sentido, importa recuperar produtos e pratos, bem como reconhecê-la como tradição, significando-a como patrimônio alimentar e potencializando-a como recurso econômico.

Esse patrimônio evoca uma referência de identidade(s), associando-o a um território e aos aspectos culturais ali presentes. Trata-se de um processo de invenção de tradições que conecta a gastronomia com a região, a cultura e as pessoas (Hobsbawm; Ranger, 2002). Apropriado pela lógica econômica, converte-se em atrativo turístico, dado que essa atividade é uma das responsáveis por sua valorização, como observa Contreras Hernandez (2005).

METODOLOGIA

Para analisar o papel do Festival Gastronômico de Taquaruçu, realizou-se uma pesquisa de campo fundamentada no método exploratório, valorizandose a técnica da descrição. Classificada como uma pesquisa não participante, o corpus da pesquisa é composto por documentos do Festival, o livro Sabores do Tocantins (Parrião, 2012) e dez entrevistas realizadas com pessoas de reconhecido saber sobre a cozinha do Tocantins: os empreendedores da 
área de alimentação, Zoé Aires Pereira - boleira; Adailde Aires da Silva dona de um restaurante na feira coberta; Ana Benedita de Cerqueira e Silva - proprietária da fábrica do Biscoito Amor Perfeito; Nair Nonato Pinto de Cerqueira - produtora artesanal de biscoitos de polvilho caseiro; Adário Martins de Almeida - vendedor de pescados; Wilton Mendonça Martins e Mirian Adriane de Oliveira Martins - proprietários da Pamonharia Paraíso; Maria Valderez Gomes Aires - coordenadora de alimentos no Colégio Militar de Palmas; o organizador do referido Festival, Hugo Maciel da Silva; e a autora do livro, Tomásia Parrião.

Ao percorrer o Estado do Tocantins, em virtude de sua inserção no Programa de Educação Alimentar para Populações de Baixa Renda, da Secretaria do Trabalho e Assistência Social (Provida), Tomásia Parrião coletou as receitas reunidas no livro Sabores do Tocantins (2012). A obra foi analisada com o objetivo de caracterizar as principais expressões culinárias e alimentares do Estado e cotejá-las aos pratos participantes do Festival.

Por sua vez, o conjunto documental do Festival Gastronômico de Taquaruçu, segundo o organizador e entrevistado Hugo Maciel da Silva, colaborador da Agência Municipal do Turismo, não contempla dados escritos sobre as edições já realizadas, tendo sido preservado parte dos registros fotográficos de quatro edições realizados pela Secom - 2007 (34 fotografias), 2009 (66 fotografias), 2011 (14 fotografias) e materiais disponibilizados no site da edição de 2013. Esse conjunto pautou-se pela descrição de seu conteúdo visando à identificação dos ingredientes, técnicas culinárias, nome dos pratos e dos critérios que fundamentaram a sua inclusão no concurso.

\section{COZINHA DO TOCANTINS: UM ESPAÇO POPULAR}

A cozinha do Tocantins revela a importância da mandioca, da carne vermelha, dos peixes de rio e dos ingredientes produzidos na região. Parte das tradições ainda sobrevive e a culinária expressa essa continuidade, segundo as receitas registradas por Tomásia Parrião no livro Sabores do Tocantins - coletânea de receitas regionais (Parrião, 2012). 
Appadurai (1988) destaca que esse tipo de publicação se inscreve em um processo de construção da cozinha nacional. Questiona as implicações desse processo de construção, bem como o seu curso e afirma que a existência de livros de receitas implica considerar a cozinha como uma variedade transmissível de conhecimento.

De acordo com Parrião (2012), tais receitas são transmitidas oralmente e preparadas, sobretudo, por mulheres, que as preservam ao longo dos anos. A troca oral de receitas constitui o processo elementar que fundamenta a elaboração dessa modalidade de publicação (Appadurai,1988).

Sabores do Tocantins (2009) inicia-se com dicas sobre "medidas sem balança", em seguida traz as receitas de cereais, carnes e aves; peixes; molhos, óleos e paçocas; bolos e lanches; sucos e chás; doces e, por último, comidas indígenas.

O modo de preparo, em sua maioria, é descrito de forma simples e preserva as particularidades locais, tais como termos, procedimentos, medidas e utensílios domésticos. Na estrutura da orientação não se observa a preocupação com o rendimento de cada receita, característica de uma cozinha simples que tem suas raízes nas práticas antepassadas. Por reproduzir a cozinha popular, algumas receitas comportam gordura em suas produções, como no biscoito realizado com "banha de porco". Na entrevista realizada, descrevem-se as características regionais da alimentação do Estado, detalhando, por vezes, a forma de preparar a iguaria:

O Estado de Tocantins é uma mistura de povos da região Norte, CentroOeste, Nordeste e Sul. Cada região do Estado tem uma maneira própria de fazer os pratos, como na região Norte, no bico do papagaio, eles utilizam muito o leite de coco de babaçu no frango e no peixe, logo é uma região onde tem muito babaçu. Já mais no Centro-Sul tem o chambari, os bolos típicos com polvilho, pois aqui no centro de Tocantins tem mais festejos [Natividade, Porto Nacional, Monte do Carmo] paçoca de carne seca, amor perfeito, bolo trovão, bolo de mãe [...] Temos também o arroz cirigado ou Maria Isabel. Na região Sudeste do Estado, nas regiões de Araias e Indianópolis utiliza muito carne de sol, tem também o arroz saia velha, do município de Paranã (Tomásia Parrião, 2013).

Uma análise pormenorizada das receitas reunidas na publicação indica a presença da carne em $27,5 \%$ do total, cuja justificativa encontra respaldo no rebanho presente no Estado. Trata-se principalmente do consumo de carne 
ISSN: 1983-7151

bovina in natura ou resultante do processo de "salga", adotado para melhor conservação por um período de tempo prolongado (carne de sol). A técnica de preparação da carne de sol remonta ao período colonial.

Os bolos e os lanches compreendem 30,5\% das receitas. Cabe destacar a valorização dos derivados da mandioca nos ingredientes incorporados às receitas: o polvilho doce ou azedo.

Na entrevista concedida, Parrião (2013) aponta a participação popular na preparação de doces para as festas religiosas, como a Festa de São Lázaro. Algumas receitas transmitidas por sua mãe foram inseridas no seu livro:

(...) doce de leite, que se chama doce de massa, coloca massa de mandioca ralada, tem o doce de banana em corte, doce de abóbora, geleia de mocotó e tem a receita típica no meu livro, esse doce é muito famoso aqui na região. Minha mãe inclusive faz essa geleia de mocotó, bolo de puba, doce de leite. (Tomásia Parrião, 2013).

Como destacado anteriormente, o costume alimentar apoia-se no consumo de certos ingredientes, em particular, destaca-se a mandioca, que "está presente na mesa do brasileiro de Norte a Sul, perpassando as mais diversas clivagens sociais, tais como classe ou etnia" (Maciel, 2004, p. 31). Ao reunir as receitas dos bolos para o livro, o autor notou o baixo consumo de farinha de trigo (cerca de 5\%), salienta, no entanto, a importância do uso da mandioca:

A mandioca é boa para fazer tudo, ela combina em tudo, como fazer ela frita, para fazer doces, para fazer bolos. Um alimento imprescindivel aqui no Tocantins é a mandioca, porque todos os pratos aqui vão a mandioca, se faz o polvilho que se faz vários tipos de bolos, onde tem o grolado, farinha seca, pirão de parida, escaldado (farinha seca no prato com leite e assa uma carne no espeto e come com esse pirão, isso antigamente). Os produtos fabricados a partir da mandioca é a farinha, polvilho é o que mais fabrica na região, com o polvilho se faz tudo, mandioca nos pratos. Aqui se consome muito o polvilho doce, mas no interior eles utilizam mais o polvilho azedo (fabricado a partir da mandioca azeda para fazer a farinha de puba). $O$ povo gosta muito da farinha de puba, onde se encontra muito nas feiras. $E$ acontece mutirão para fazer a farinhada. (Tomásia Parrião, 2013).

No seu relato, aponta o caráter conservador dessa cozinha que pouco se renova, com predomínio de composições realizadas com a mandioca, tanto nos doces quanto nos salgados: "Os pratos que utilizam a mandioca é a costela, 
o chambari, a paçoca, carne-seca com mandioca que se chama de picadinho, bolos principalmente que utiliza o polvilho" (Tomásia Parrião, 2013). Essas preparações estão presentes nos restaurantes da capital do Estado, de acordo com os entrevistados e comprovação in loco.

A importância da mandioca também é ressaltada por Maria Valderez Gomes Aires (2013), outra entrevistada. Destaca tanto o aspecto econômico quanto o cultural e salienta a produção e tipologia dos subprodutos extraídos, bem como as principais iguarias presentes no Estado. De acordo a entrevistada, o caráter conservador desse legado inibe a criação de novas receitas:

A mandioca tem seu valor econômico devido trazer divisas para nosso Estado, como garantir uma fonte de renda para a população mais pobre. Cultural devido nos grandes festejos eles fazem pratos típicos feitos a partir da mandioca com o polvilho, mas os mais utilizados em festejos são o bolo de mandioca e a paçoca de carne de sol que é feita com farinha de mandioca (puba ou branca). Os produtos fabricados a partir da mandioca é o polvilho, farinha, bolos, beiju. Para a fabricação dos produtos a base da mandioca é feita em mutirão, como a farinha de mandioca, que leva vários processos até o preparo final. Começa já no plantio e vai até sua preparação, porque precisa descascar a mandioca, triturar, por isso precisa de mão de obra para seu preparo. Os pratos que utiliza a mandioca é a paçoca de carne de sol, costela com mandioca, beiju, mangulão, peta, bolo cacete. [...] Nunca elaborei prato diferente com a mandioca, só mesmo os típicos da nossa região. Temos alguns tipos de mandioca: cacau (amarela), macaxeira (branca) e a preta (casca escura). (Maria Valderez Gomes Aires, 2013).

A farinha de mandioca tem valor e importância para o povo tocantinense, pois é uma fonte de energia acessível para a maioria da população. A dimensão de sua importância é atestada por Cascudo (2004, p. 93): "[...] é a camada primitiva, o basalto fundamental na alimentação brasileira".

Legado familiar, as iguarias realizadas com produtos oriundos da mandioca são preparadas cotidianamente e integram tanto os momentos de convivialidade doméstica quanto os de recepção de amigos e familiares.

A mandioca é muito utilizada na culinária do dia a dia, logo comemos sempre com farinha de mandioca, para fazer um biscoito para o café da manhã e da tarde. A mandioca é importante na nossa culinária porque ela é nutritiva e traz fonte de renda para nossa população. (Maria Valderez Gomes Aires, 2013). 
A demanda por essas iguarias motiva a produção artesanal e a comercialização de acordo com a boleira, de Porto Nacional, Zoé Aires Pereira e a proprietária da fábrica de biscoitos Amor-Perfeito, de Natividade, Nair Nonato Pinto de Cerqueira, mais conhecida como Dona Naninha, empreendedora que há mais de 40 anos faz biscoitos de polvilho caseiros para vender em sua residência, utilizando um forno a lenha no fundo do quintal.

A cozinha típica é apresentada por Maciel (2001, p. 152):

A constituição de uma cozinha típica vai assim mais longe que uma lista de pratos que remetem ao "pitoresco", mas implica no sentido destas práticas associadas ao pertencimento. Nem sempre o prato considerado "típico", aquele que é selecionado e escolhido para ser o emblema alimentar da região é aquele de uso cotidiano. Ele pode, sim, representar o modo pelo qual as pessoas querem ser vistas e reconhecidas.

Essa reflexão motivou a elaboração do questionamento do que seria o prato típico de Tocantins, e os entrevistados foram unânimes ao destacarem o Arroz Cirigado ou Maria Izabel, todavia, como se verá adiante, ele não é comercializado no Festival Gastronômico de Taquaruçu.

\section{O PAPEL DO FESTIVAL GASTRONÔMICO DE TAQUARUÇU NA CONCEPÇÃO DE UMA GASTRONOMIA PARA TOCANTINS}

O Festival Gastronômico de Taquaruçu foi criado em 2007 com o intuito de valorizar a culinária regional, incentivar o empreendedorismo na área gastronômica, trazer divisas para Taquaruçu e região e divulgar os produtos típicos da culinária tocantinense. Organizado e divulgado pela Agência Municipal de Turismo, objetiva definir uma identidade gastronômica para o Estado, que ainda está em formação.

Esse processo desencadeia a associação dos hábitos alimentares a um território e, no caso em questão, ao associar a culinária regional a Palmas, constrói uma identidade, concorrendo também para a definição do patrimônio alimentar do Estado. Essa vinculação dos produtos, recursos e tradições ao território é salientado por Montanari (2013, p. 137): 
Assim como os produtos, os pratos também se mostram, talvez desde sempre, vinculados ao território, aos recursos, às tradições. Mas também nesse caso se delineia historicamente um objetivo impróprio: não mais distinguir as especialidades e utilizá-las como sinal identificador de culturas diversas, mas ajuntá-las, confundilas, misturá-las.

Essa construção cultural, real ou imaginária, voluntária ou estimulada, resulta na sua construção como produto de divulgação no cenário regional e nacional, constituindo-se em um potencial atrativo turístico. Ao consumir o alimento pertencente ao patrimônio alimentar da região, o comensal se conecta com suas tradições e reforça o aspecto identitário que o fundamenta.

A criação do festival gastronômico segue a iniciativa desenvolvida por outras municipalidades, como o Festival de Cultura e Gastronomia de Tiradentes/ MG, cuja capacidade de atração de visitantes e turistas e, consequentemente, geração de recursos econômicos, conferem visibilidade a essa modalidade de evento no cenário nacional. Dentre seus objetivos evidenciam-se "reunir chefs, dar oportunidade à formação profissional, oferecer workshops, desenvolver a alta gastronomia no Brasil e melhorar o fluxo de turistas na cidade de Tiradentes" (Furtado, 2015, p. 84). Por sua vez, a maioria dos festivais de gastronomia na Turquia comercializa alimentos regionais em barracas, exibem músicas, realizam shows e competições. Organizados nas aldeias costeiras, objetivam prolongar a atividade turística nos períodos de baixa estação, segundo Kesimoglu (2015).

Criado em 1998, o Festival de Cultura e Gastronomia de Tiradentes/MG se caracteriza pela produção de pratos realizados por profissionais do Brasil e do exterior. Furtado (2015) realiza uma cronologia do Festival e sistematiza as temáticas de cada edição em sua tese de doutorado, e afirma que, antes de Tiradentes, festivais de alta gastronomia eram realizados em hotéis cinco estrelas nas cidades do Rio de Janeiro e de São Paulo.

Diferentemente da edição de Tiradentes/MG, cuja temática varia a cada ano, o uso de ingredientes regionais na preparação das iguarias em Taquaruçu constitui um dos critérios para a participação no referido festival. Nas fotografias, passíveis de identificação dos ingredientes predominantes, constatam-se carne de sol (2007 e 2009) e carne bovina (2011), mandioca e 
seus derivados (2007, 2009 e 2011), coco de babaçu (2007), banana-da-terra ou pacova (2007 e 2009), macaúba (2007) e pequi (2009). A documentação fotográfica realizada por iniciativa da Secom revela a introdução de novas composições (desses ingredientes) e distintas formas de apresentação, ou seja, inaugura tendências. Em certo sentido, ao afirmar a cozinha do Tocantins, o evento colabora com o processo de "invenção" da gastronomia desse Estado.

Figuras 4 e 5 - Caramelizado de mandioca ao leite de babaçu e pavê de macaúba.

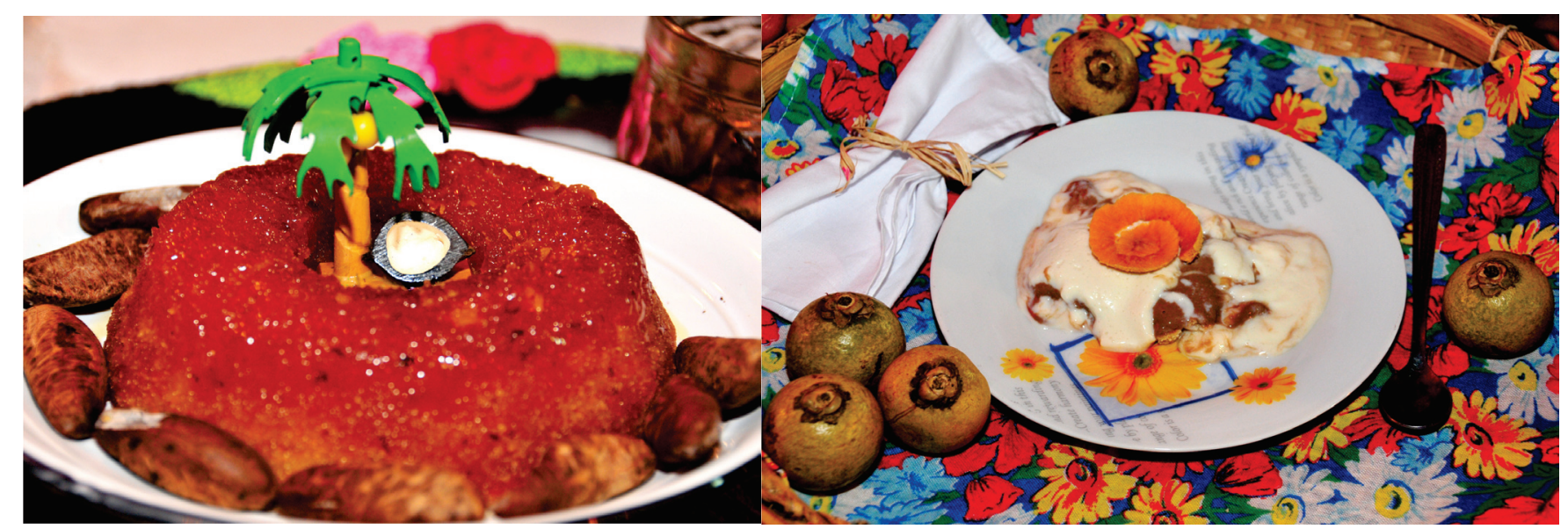

Fonte: Secom (2007).

Na edição de 2007, por exemplo, havia pratos com produtos típicos da região, como picadinho ao molho picante, caramelizado de mandioca ao leite de babaçu (figura 4), cuscuz de carne de sol, pavê de macaúba (figura 5), cocada assada, carne de sol com pirão de queijo, Maria Isabel no azeite de coco com queijo e fios de cana-de-açúcar, galinhada e caldo de chambari.

Figuras 6 e 7 - Pudim de cupuaçu com farinha de tapioca e tucunaré empanado com molho de açaí e chips de cará.

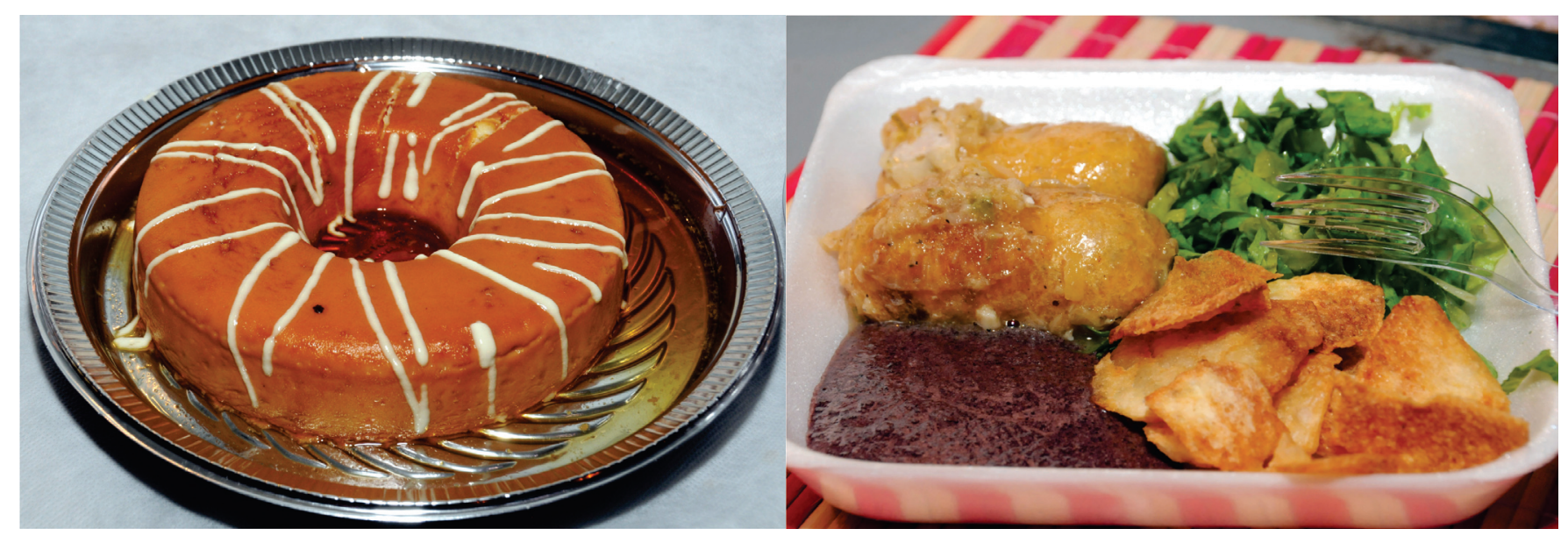


Fonte: Secom (2009).

Em 2009, foram elaborados pratos como polenta com carne-seca, bobó de camarão, pudim de cupuaçu com farinha de tapioca (figura 6), baião de três (carne, feijão e queijo), canjica de leite de coco, fava à moda tropeira, linguiça de tucunaré ao molho de açaí, ricoxi da serra, galinhada caipira ao molho pardo, tapiocas (carne de sol, mel com banana e canela), panqueca sabor do Tocantins, escondidinho de couve e abacaxi, arroz de lentilha com carne de sol desfiada, lasanha de milho da serra, cozido de vitelo com vinho tinto, frango à jardineira, frango ao creme de pequi e tucunaré empanado com molho de açaí e chips de cará (figura 7).

De acordo com os dados fotográficos, em 2011, os pratos que concorreram foram beiju, panquecas, pavê de coco, pudi0m de jabuticaba, tapioca e pão de queijo recheado, entre outros.

A sétima Edição do Festival Gastronômico de Taquaruçu foi realizada entre os dias 15 e 18 de agosto de 2013. As inscrições aprovadas passaram a ser divulgadas, bem como os critérios para a avaliação dos jurados, além do resultado do concurso, estipulando-se premiação do primeiro ao terceiro colocado. Entre os quesitos reunidos na Portaria (2013) para a eleição das iguarias, destacam-se apresentação, criatividade e originalidade, bem como avaliação do atendimento, higiene, decoração interna e organização do estande, como segue:

Os jurados seguiram dois critérios, o do prato, avaliando degustação, originalidade e criatividade e a apresentação; e do requisito estande, no qual avaliaram a organização, a decoração, o atendimento, a igiene e a limpeza. Tanto os estandes, como as mesas e cadeiras foram cedidos pela Prefeitura de Palmas, competindo aos inscritos à decoração interna. A Agtur (Agência de Turismo) optou pela padronização das mesas, todas brancas e forradas, e da fachada externa dos estandes identificados com o nome do prato e do Chef responsável pela receita visando a uma identidade visual harmônica e prezando a higiene, que credibiliza o Festival. (http://conexaoto.com.br). 
Nessa edição, constata-se o acréscimo do número de participantes, de 40 pratos foram para 56 , dos quais 35 salgados ${ }^{3}$ e 21 doces. ${ }^{4}$ Embora parte dos nomes desses pratos ostente o de pelo menos um dos ingredientes, isso não se aplica a todos, inviabilizando o mesmo tipo de análise realizada com as fotografias das edições 2007, 2009 e 2011. Das informações existentes, constatam-se pratos elaborados com carne-seca, mandioca, cupuaçu e babaçu.

Segundo os dados obtidos no site do portal do estado de Tocantins, os pratos vencedores foram: salgados - Torta de carne de sol com creme de abóbora, Pastel de filé de tucunaré e Bem bolado da Dalila; e doces - Churros gelados com chocolate e recheio de cupuaçu e sorvete, Pizza de pamonha doce e Surpresa de bananas. Esse resultado revela a perspectiva que fundamenta a realização do concurso, ou seja, a valorização dos ingredientes regionais e a criatividade na elaboração dos pratos. Nítida é a influência dos ingredientes da Região, com o tucunaré e o cupuaçu, bem como a carne-seca e o milho.

\begin{abstract}
A 7ạ Edição do Festival Gastronômico de Taquaruçu tem como tema principal a valorização dos ingredientes culinários regionais e a criatividade na elaboração dos pratos, os quais obrigatoriamente devem ser típicos da culinária tocantinense. O objetivo do festival é o fortalecimento da identidade gastronômica local e o turismo. (http://conexaoto.com.br).
\end{abstract}

3 Os pratos salgados participantes, de acordo com o site de Tocantins (conexaoto.com.br), são: Rocambole de madioca e carne de sol; Baião de dois Sabor da Serra; Feijoada desconstruída com farofa de buriti; Taquarepuba; Arroz especial com carne-seca e uvas passas; Aperriê com óleo de coco Babaçu; Caipirão de linguiça e bacon com creme babaçu; Macarrão à bolonhesa com creme de abóbora, requeijão e cebolinha; Peixe frito ao óleo de coco babaçu; Torta de carne de sol com creme de abóbora; Mucuza; Macarronada tocantinense; Pastel de frango caipira com pequi e queijo; Galinha caipira com pirão de milho; Escondidinho de camarão ao leite de coco babaçu; Pirão de queijo com carne de sol; Acarajé com pequi; Macarrão na chapa com creme de gergelim; Beiju com coco babaçu; Chica doida; Panelinha de taquaruçu; Pastel de filé de tucunaré; Pato no pequi e tucupi; Creme de cocoricó; Torta da serra com carne de sol desfiada; Escondidinho de carne de sol com macaxeira; Frango ao molho verde; Lagarto de sol com salada de bifum; Picadinho de carne ao molho branco picante; Caldeirada de peixe tucunaré; Feijão tropeiro à moda da serra; Salpicão de galinha caipira; Galinha caipira ao molho de leite de coco; Torta de carne-seca com massa de iogurte; Bife ao molho de coco; Torta escondida com arroz de castanha.

4 Os pratos doces participantes da edição 2013, de acordo com site de Tocantins (conexaoto. com.br), são: Flocos de tapioca com creme de cajá; Veia fogosa; Musse de abóbora; Churros gelados com chocolate e recheio de cupuaçu e sorvete; Chocolate quente ao chantilly; Torta de cupuaçu; Musse de murici; Delícia de abacaxi com creme; Musse de buriti; Tapioca com recheio de doce de buriti com creme de ricota; Beiju tocantinense; Brigadeiro de amor-perfeito; Pizza de pamonha doce; Torta de banana caramelizada com chocolate; Bolo de leite em pó e coco babaçu; Pavê tocantinense ao molho de babaçu; Pudim de milho; Surpresa de bananas; Torta light de manga; Gelatina de abacaxi ao leite de coco babaçu. 
Nos pratos salgados, predominam ingredientes tidos como tradicionais da cozinha de Tocantins, como buriti, coco babaçu, pequi, tucunaré, carne de sol, milho, macaxeira e castanha de caju. Já nos pratos doces, os ingredientes que são passíveis de serem identificados: tapioca, cajá, cupuaçu, murici, buriti, milho e coco babaçu. Nota-se que alguns ingredientes são comuns tanto na elaboração dos pratos doces quanto na dos salgados, como coco de babaçu, tapioca e milho. Outra questão importante é a valorização da carne bovina, dos 36 pratos salgados inscritos, 20 utilizaram a carne como ingrediente principal e quatro valem-se da mandioca.

Como indicado pelos pratos presentes no festival, há a predominância da utilização da carne bovina, aspecto generalizado no território nacional, como atesta Lody (2013, p. 11):

A carne tem um valor especial dentro das nossas cozinhas regionais. É uma comida considerada nobre; uma comida que retoma formas ancestrais das caças imemoriais dos provedores, dos caçadores, daqueles que dão de comer, e, junto com tudo isso, há também o sentimento do bem comer. Pois comer bem é comer com carne.

Segundo Hugo Maciel da Silva (2013), a valorização da culinária regional no festival objetiva utilizar ingredientes do cerrado, nas categorias doce e salgado:

Os participantes têm a oportunidade de ter uma renda extra, o que é extremamente importante para o pessoal que mora lá. Salientou o aspecto cultural que permeia o evento: A culinária está totalmente vinculada à cultura, desenvolvimento de um prato, caracterização, apresentação do prato utilizando ingredientes da culinária regional, isso de certa forma valoriza a nossa culinária.

Ao ser indagado sobre a iguaria representativa do Estado destacou, sobretudo, os salgados: "A paçoca de Arrais, o chambari de Paraíso, amor-perfeito, peixe (Tucunaré), buchada e a galinha caipira (Hugo Maciel da Silva, 2013)".

Gomes e Barbosa (2004, p. 9) salientam esse predomínio do salgado na alimentação brasileira: "A observação atenta da distribuição entre os sabores demonstra cabalmente a predominância do salgado sobre o doce em todas as circunstâncias da vida alimentar brasileira". 
Organizado em barracas dispostas ao longo da via, o Festival Gastronômico de Taquaruçu não absorve os restaurantes da cidade na sua edição. Concebido com escopo diversificado, o Festival de Tiradentes englobou esses equipamentos, bem como hotéis, além de incluir espetáculos culturais, fórum e tour gastronômico, cursos, palestras e stands empresariais. Objetivava atrair um turista diferenciado ao oferecer tanto a cozinha tradicional mineira, quanto a alta gastronomia internacional. Resultou na sua consolidação no cenário nacional, investimentos em infraestrutura na cidade e no incremento de $300 \%$ do setor de serviços em 10 anos (Furtado, 2015).

\section{CONSIDERAÇÕES FINAIS}

Associada aos ingredientes específicos, a cozinha tocantinense possui particularidades em cada região, resultado dos produtos ali cultivados, da criação de peixes (em cativeiro), pequenos animais (porco, galinha) e do rebanho bovino, além dos legados e das tradições culinárias ali reunidas. Notase uma cozinha cotidiana que valoriza a mandioca e a carne bovina, destacamse receitas tradicionais de bolos e biscoitos feitos à base de polvilho.

Constata-se que o processo de afirmação da gastronomia tocantinense relaciona-se às pessoas que ali se encontram, seus antepassados e receitas transmitidas pela oralidade, repetidas e atualizas à medida que se instaura a redução da diversidade botânica e se estabelece a padronização alimentar, bem como os padrões urbanos de consumo.

Com relação ao papel do Festival Gastronômico de Taquaruçu na "invenção" da cozinha de Tocantins, apesar de prescrever o uso de ingredientes regionais na preparação das iguarias como um dos critérios para a participação no referido festival, nota-se que não contempla a cozinha tradicional cotidiana. Preocupa-se com a apresentação dos pratos e com a renovação culinária, contudo a consolidação da gastronomia tocantinense também depende da valorização de sua cozinha tradicional, além dos ingredientes regionais, garantindo a preservação de sua diversidade botânica e a constituição do seu patrimônio gastronômico. 
A repetição de certos ingredientes constitui um recurso de afirmação, estratégia mobilizada no processo de "invenção" dessa gastronomia, como se fosse única e não plural. A introdução de novas composições desses ingredientes e as distintas formas de apresentação inauguram tendências e exibem a criatividade na elaboração dos pratos. Em certo sentido, o evento cria uma gastronomia desse Estado em via de consolidação, reforça a importância de Palmas na condução desse processo de construção de identidade política do Estado, mas não divulga as manifestações e as expressões culinárias e alimentares tradicionais ainda existentes.

A exemplo dos festivais de gastronomia de Tiradentes e da Turquia, persegue o incremento da visitação turística, todavia um leque de oportunidades pode ser vislumbrado na medida em que reinterprete as especificidades locais para incorporar os empreendedores do setor de alimentos e bebidas, hotéis e outras secretarias do Município para o seu fortalecimento e expansão.

\section{REFERÊNCIAS}

Abreu, E. S.; Viana, I. C.; Moreno, R. B.; Torres, E. A. F. S. (2001). Alimentação mundial: uma reflexão sobre a história. Saude Soc. [online], v. 10, n. 2, p. 3-14.

Appadurai, A. (1988). How to make a national cuisine: cookbooks in contemporary India. Comparative Studies in Society and History. v. 30, n.1, p. 3-24, jan.

Aron, J. P. (1989). Cozinha. In: Einaldi. Homo domesticação. Cultura Material. Porto: Imprensa Nacional/Casa da moeda, v. 16, p. 281-304.

Cavalcante, M. E. S. R. (2003). O discurso autonomista do Tocantins. Goiânia: Ed. da UCG.

Carneiro, H. S. (2005). Comida e Sociedade: significados sociais na historia da alimentação. História: Questões \& Debates, Curitiba: Editora UFPR, n. 42, p. 71-80.

Contreras Hernández, J. (2005). Patrimônio e globalização: o caso das culturas alimentares. In: Canesqui, A. M. \& Garcia, R. W. Antropologia e nutrição: um diálogo possível (pp. 129146). Rio de Janeiro: Fiocruz.

Dória, C. A. (2014). Formação da culinária brasileira. Escritos sobre a cozinha inzoneira. São Paulo: Três Estrelas. 
Flandrin, J. L.; Montanari, M. (1988). História da alimentação. 4. ed. São Paulo: Estação Liberdade.

Franco, Ariovaldo. (2001). De caçador a gourmet: uma história da gastronomia. São Paulo: Senac.

Furtado, S. M. (2015). Indústrias criativas: Festival de Cultura e Gastronomia de Tiradentes/ Minas Gerais/Brasil. 2015. Tese (doutorado em Ciências Sociais). São Paulo: Pontifícia Universidade Católica de São Paulo (PUC/SP).

Gomes, L. G.; Barbosa, L. (2004). Culinária de papel. Estudos históricos. Rio de Janeiro, n. 33, p. 3-23, jan./jun.

Hobsbawm, E., \& Ranger, T. (2002). A invenção das tradições. Rio de Janeiro: Paz e Terra.

Kesimoglu, A. (2015). A reconceptualization of gastronomy as relational and reflexive. Hospitality \& Society. v. 5, n.1, p. 71-91.

Lody, R. (2013). Farinha de mandioca - o sabor brasileiro e as receitas da Bahia. São Paulo: Senac São Paulo.

Maciel, M. E. (2004). Uma cozinha à brasileira. Estudos históricos (Rio de Janeiro), Rio de Janeiro, v. 33, p. 25-39.

Maciel, M. E. (2001). Cultura e alimentação ou o que têm a ver os macaquinhos de Koshima com Brillat-Savarin. Horizontes Antropológicos, Porto Alegre, ano 7, n. 16, p. 145-156, dez.

Montanari, M. (2013). Comida como cultura. 2. ed. São Paulo: Senac São Paulo.

Oliveira, R. (2004). A invenção do Tocantins. In: Giraldin, O. (org.). A (trans)formação histórica do Tocantins. 2. ed., Goiânia: UFG, p. 13-48.

Parrião, T. (2009). Sabores do Tocantins: coletânea de receitas regionais. 2. ed., Palmas: s.n.

Portaria/GAB/AGTUR N. 05/2013, de 31 de julho de 2013.

Revel, J. F. (1996). Um banquete de palavras: uma história da sensibilidade gastronômica. São Paulo: Companhia das Letras.

Santos, C. R. A. (2011). A comida como lugar de história: as dimensões do gosto. História: Questões \& Debates, Curitiba: Editora UFPR, n. 54, p. 103-124, jan/jun.

Santos, C. R. A. (2005). A alimentação e seu lugar na história: os tempos da memória gustativa. História: Questões \& Debates, Curitiba: Editora UFPR, n. 42, p. 11-31. 
Santos, F.G. (2014). Da criação do Estado de Tocantins à invenção de sua gastronomia. Dissertação (Mestrado em Hospitalidade). São Paulo: Universidade Anhembi Morumbi.

Silva, O. B. (1997) Breve História do Tocantins e de sua gente: uma luta secular. Araguaína: Federação das Indústrias do Estado de Tocantins. Brasília: Solo Editoras.

Teixeira, L. F. C. (2009) Formação de Palmas. Revista UFG, junho, Ano XI, n. 6.

SITES CONSULTADOS

Conexaoto. Disponível em: < http://conexaoto.com.br>. Acesso em: 12 dez. 2013.

Guia Net. Disponível em: <www.guianet.com.br/to/mapato.htm>. Acesso em: 12 dez. 2013.

Sogeografia. Disponível em: <www.sogeografia.com.br/Mapas/Estados/to.gif>. Acesso em: 10 mai. 2013. 